\title{
Treatment of end stage dilated cardiomyopathy
}

\author{
John B O'Connell, Charles K Moore, H Chris Waterer
}

Dilated cardiomyopathy continues to be a serious clinical problem with about 20000 new patients affected in the United States each year. By definition, the cause of injury to the myocardium is unknown. ${ }^{1}$ Consequently, treatment is purely symptomatic because it cannot be specifically directed toward aetiology. In most cases, the major symptomatic presentations of dilated cardiomyopathy, arrhythmia, embolic phenomena, and congestive heart failure, are successfully managed, at least initially, by conventional treatment. However, if myocardial injury persists or is so severe that conventional treatment does not palliate the symptoms, cardiac transplantation remains the only viable alternative. In fact, $50 \%$ of those undergoing cardiac transplantation have dilated cardiomyopathy. ${ }^{2}$ In the present paper we describe the conventional management of dilated cardiomyopathy and discuss new approaches that may prolong survival and reduce morbidity.

\section{Management of congestive heart failure VOLUME OVERLOAD AND EXERCISE}

The management of congestive heart failure in patients with dilated cardiomyopathy differs little from the management of patients with specific heart muscle diseases or other causes of left ventricular dysfunction (table 1). Volume overload owing to salt and water retention is prominent. Sodium and water restriction are appropriate and diuretics are indicated. Loop diuretics (frusemide, bumetanide, etc) are preferred. When the dose of loop diuretics is increasing and the response diminishing, the addition of a thiazide (metolazone) to the loop diuretic may be of additional benefit. ${ }^{3}$ With low cardiac output and an oedematous gut intestinal absorption may be poor. An intravenous bolus or continuous infusion of frusemide may be successful when high oral doses do not induce the desired diuretic effect. ${ }^{4}$ Ultrafiltration can reduce fluid overload in severe refractory congestive heart failure. ${ }^{5}$ Patients with symptoms and physical findings of volume overload should be treated with diuretics. Patients without evidence of volume overload, dyspnoea, or peripheral oedema do not require diuretic treatment.

Though bed rest is appropriate during the acute presentation of congestive heart failure, a programme of progressive physical activity may improve exercise tolerance and enhance functional capacity in patients with dilated cardiomyopathy. Supervised exercise training has beneficial haemodynamic and metabolic effects. ${ }^{67}$ Anaerobic (isometric) exercise should be avoided and aerobic training encouraged.

\section{VASODILATORS}

Reduction of preload and afterload improves cardiac efficiency and ejection fraction in patients with left ventricular dysfunction. The angiotensin converting enzyme inhibitors are most widely applied for this purpose. Short term treatment with captopril, the prototype of this class of drugs, reduces systemic vascular resistance and filling pressures, increases cardiac output, and improves exercise tolerance. The haemodynamic benefit is sustained during long term treatment. ${ }^{8}$ Other angiotensin converting enzyme inhibitors have similar haemodynamic properties. ${ }^{9}$ The cooperative north Scandinavian enalapril survival study (CONSENSUS) concluded that patients with severe symptomatic limitation (New York Heart Association (NYHA) class III and class IV) and a markedly reduced ejection fraction have a significant survival benefit at one year if randomly assigned to receive enalapril plus conventional therapy compared with a control group treated with placebo plus conventional therapy. ${ }^{10}$ In the Studies of Left Ventricular Dysfunction (SOLVD) the survival of patients who were less severely ill than those studied in CONSENSUS also improved when enalapril was added to conventional treatment. ${ }^{11}$ In the SOLVD prevention arm the development of congestive heart failure and instances of hospital admission with congestive heart failure were reduced (by $37 \%$ and $36 \%$ respectively) in symptom free patients with abnormal systolic function. ${ }^{12}$ This finding emphasises the importance of angiotensin converting enzyme inhibitors. ${ }^{12}$ Therefore, angiotensin converting enzyme inhibitors must be regarded as standard treatment for dilated cardiomyopathy. Unfortunately, it is estimated that only $25 \%$ of those with congestive heart failure in the United States receive angiotensin converting enzyme inhibitors. Alternative vasodilators may be necessary in about $20 \%$ of patients who do not tolerate the agents because of renal dysfunction, hypotension, hyperkalaemia, or cough. ${ }^{13}$

In the first Veterans heart failure trial (VHEFT I) the survival of moderately symptomatic patients with abnormal systolic function was better when a combination of hydralazine and isosorbide dinitrate was given compared with prazosin or placebo. ${ }^{14}$ In the $\mathrm{Hy}-\mathrm{C}$ trial, captopril alone was more efficacious than the 
Table 1 Conventional management of congestive heart failure in dilated cardiomyopathy

- Sodium and water restriction

- Diuretics

- Angiotensin converting enzyme inhibition if tolerated

Table 2 Positive inotropic agents in the management of dilated cardiomyopathy

- Digitalis glycosides

- Intravenous $\beta$ adrenergic agonists (dobutamine and dopamine)

- Phosphodiesterase inhibitors (amrinone, milrinone)

Quinolinones (flosequinan, vesnarinone, OPC18790) hydralazine/isosorbide dinitrate combination. ${ }^{15}$ The V-HEFT II study confirmed that mortality was lower in patients treated with enalapril than in those randomised to hydralazine/isosorbide dinitrate. ${ }^{16}$ None the less, this combination remains a useful alternative in those who are intolerant of angiotensin converting enzyme inhibitors.

The fluorinated quinolinone, flosequinan, has vasodilatory and inotropic properties. ${ }^{17}$ In FACET, patients treated with intermediate doses of flosequinan (100 $\mathrm{mg} v$ placebo) in addition to ACE inhibitors exercise tolerance increased and quality of life improved. ${ }^{18}$ Unfortunately, preliminary unpublished analysis of the PROFILE study demonstrated enhanced mortality at this dose: this suggests a greater inotropic effect than previously recognised. The effect of low dose $(\leqslant 75 \mathrm{mg}$ day) flosequinan on mortality remains unclear.

Calcium channel blockade was shown to be of benefit when diltiazem was added to conventional treatment in patients with dilated cardiomyopathy and mild to moderate congestive heart failure. ${ }^{19}$ However, diltiazem's known negative inotropic properties have deterred intensive clinical investigation. Calcium channel blockade with a less negatively inotropic agent, amlodipine, showed improved exercise tolerance in this subgroup..$^{20}$ Before calcium channel blockade can be regarded as adjunctive therapy in dilated cardiomyopathy, multicentre trials, which are underway, must show a beneficial effect.

\section{INOTROPES (TABLE 2)}

Digitalis glycosides are the historical cornerstone of treatment for congestive heart failure. Accurate doses have replaced the tea brewed with the foxglove leaves by Withering in 1785 , but the mechanism of the beneficial effect has come into question and randomised withdrawal studies have only recently shown its efficacy. Although digitalis glycosides block sodium/potassium ATPase and increase intracellular calcium through passive sodium/calcium exchange, they also modify cardiac sympathetic activity, which suggests that they have a modulating effect on baroreceptor reflexes. ${ }^{21}$ Not enough is known about this effect to attribute any beneficial effect to modulation of neural activity. The efficacy of digoxin has been questioned. However, the randomised assessment of digoxin and inhibitors of angiotensin converting enzyme (RADIANCE) study showed clinical deterioration in patients with chronic congestive heart failure and sinus rhythm when they are randomly withdrawn from treatment with digitalis glycosides. ${ }^{22}$ In those randomised to long term oral digoxin the beneficial effect was retained. Consequently, the debate regarding the efficacy of this age-old treatment has become less intense. Only its effect on mortality remains in question and awaits the completion of a trial sponsored by the National Institutes of Health.

The selective $\beta$ adrenergic agonist, dobutamine, is effective for the short-term manage- ment of congestive heart failure or exacerbations of chronic heart failure when given as an intravenous infusion to doses of 10 $\mu \mathrm{g} / \mathrm{kg} / \mathrm{min} .^{23}$ Attempts to develop oral $\beta$ adrenergic agonists for the long-term treatment of heart failure have been frustrated by the rapid development of tolerance, ${ }^{24}$ which presumably is associated with down regulation of $\beta$ adrenergic receptors. In patients with severe congestive heart failure, the beneficial effect of brief (three to four day) infusions of dobutamine may be sustained. ${ }^{25}$ This observation served as the rationale for intermittent infusions of dobutamine in ambulatory patients. Many protocols for intermittent infusion have been proposed and there is no consensus on the duration of infusion and interval between infusions. ${ }^{26}$ Additionally, the technological advances in the design of infusion pumps allow patients to be maintained on continuous intravenous dobutamine as outpatients. Such treatment is usually reserved for patients awaiting cardiac transplantation. ${ }^{27}$ Despite the apparent acceptance of this approach, randomised prospective trials designed to document efficacy have not been completed.

The phosphodiesterase inhibitor amrinone was developed as a positive inotropic agent for short-term intravenous infusions. ${ }^{28}$ The phosphodiesterase inhibitors are effective inotropes with vasodilating properties. The effect is most pronounced when combined with $\beta$ adrenergic agonists. ${ }^{29}$ These additive effects are often helpful in patients awaiting cardiac transplantation. ${ }^{30}$ Because long-term treatment with amrinone is associated with thrombocytopenia, the analogue milrinone was developed. Milrinone can be given either by mouth or intravenously. The acute haemodynamic effects of milrinone and amrinone are similar. However, in the prospective randomised milrinone survival evaluation (PROMISE) trial cardiovascular mortality was $34 \%$ higher in those on long-term oral treatment. ${ }^{31}$ Consequently, clinical research on long-term oral administration of the phosphodiesterase inhibitors essentially has been suspended. Therefore, the digitalis glycosides are the only oral positive inotropic agents available for use in patients with chronic congestive heart failure.

\section{NEW TREATMENTS}

Vesnarinone/OPC18790

Vesnarinone (OPC8212), an orally active quinolinone, has recently been developed for the treatment of congestive heart failure. ${ }^{32}$ Although it has mild inhibitory effects on phosphodiesterase III, vesnarinone also delays outward and inward potassium currents and opens sodium channels, prolonging the action potential and slowing heart rate. The mechanism of action is not dissimilar to that of the antiarrhythmic agent sotalol. In a randomised prospective trial of more than 500 patients with symptomatic congestive heart failure and ejection fraction $<30 \%$, an intermediate dose of vesnarinone $(60 \mathrm{mg} /$ day) reduced all cause morbidity and mortality by more than $50 \%$ 
and quality of life improved significantly. ${ }^{33}$ The high dose arm $(120 \mathrm{mg})$ increased mortality. Neutropenia occurred in $2.5 \%$ of the patients receiving the agent. This drug is currently under continued phase III clinical trials. An intravenous analogue, OPC18790, is entering clinical trials.

\section{$\beta$ Blockers}

The adverse effect of neurohormonal activation is underscored by the efficacy of $\beta$ adrenergic blockade in the treatment of congestive heart failure. The metoprolol in dilated cardiomyopathy (MDC) trial showed a reduction in cardiovascular morbidity and improved ejection fraction in more than 300 patients with dilated cardiomyopathy and congestive heart failure. ${ }^{34}$ Although tolerance to $\beta$ adrenergic blockade is quite good overall, the dose titration phase can exacerbate congestive heart failure in some patients and so delay the achievement of the maximum targeted dose. Some new $\beta$ blockers have vasodilating properties that improve tolerance and reduce the difficulty with dose titration. Vasodilation by bucindolol is mediated by a nitrile-like component, and carvedilol has weak $a$ blocking properties. $^{35}$ Compared with metoprolol, short-term treatment with carvedilol increased the cardiac index, decreased systemic vascular resistance, and decreased filling pressures-a reflection of the vasodilator effect. Long-term treatment with bucindolol produced a sustained increase in ejection fraction. ${ }^{36}$

The mechanism of action of $\beta$ blockade is unknown. Initially, it was thought that up regulation of the $\beta$ receptor that resulted from long-term treatment with metoprolol was the major mechanism of action. ${ }^{37}$ However, clinical and haemodynamic improvement was detected with carvedilol treatment in the absence of up regulation of these receptors. ${ }^{38}$ Perhaps the major mechanism of action is simply blockade of the receptors and a reduction of the adverse effects of catecholamines on the failing human heart.

Vesnarinone and $\beta$ blockade may prove to be major additions to the treatment of dilated cardiomyopathy. Additionally, if the definitive clinical trials show survival similar to the improvement reported in the preliminary studies, the outcome with this approach in patients with NYHA class III symptoms will be comparable to cardiac transplantation.

\section{Anticoagulation}

Patients with dilated cardiomyopathy are susceptible to thromboembolic phenomena, because of poor peripheral perfusion and low flow, and to the formation of mural thrombi, particularly when the ejection fraction is $<30 \%$. $^{39}$ The likelihood of an embolic episode is approximately $30 \%$ over a two year follow up in patients with a low ejection fraction and decompensated congestive heart failure. Therefore, it is logical to consider long-term oral anticoagulant treatment in these patients. However, regulation of anticoagulant treatment may be particularly difficult because the patients who are most likely to benefit, those with poorly controlled congestive heart failure, have hepatic congestion and subsequent autoanticoagulation. Recently, the broad based recommendation for chronic anticoagulant treatment in patients with dilated cardiomyopathy has been questioned because no prospective clinical trials showing its efficacy and defining its morbidity have been completed. Therefore, long-term oral anticoagulation is commonplace but not of proven benefit.

\section{Antiarrhythmic treatment}

Ventricular arrhythmias are common in patients with dilated cardiomyopathy. In fact, over $70 \%$ of these patients have non-sustained ventricular tachycardia during ambulatory monitoring. ${ }^{40}$ The arrhythmias may be inducible in the electrophysiology laboratory but a correlation between ventricular arrhythmias and sudden death in dilated cardiomyopathy has never been confirmed. ${ }^{41}$ Decompensated congestive heart failure itself is commonly associated with ventricular arrhythmias.

Antiarrhythmic treatment is fraught with difficulty in this group of patients because of the arrhythmogenic effects and negative inotropic properties of most antiarrhythmic agents. Antiarrhythmic agents should be avoided if possible and only used in those patients with symptomatic ventricular arrhythmia. Selected patients with recurrent, symptomatic, uniform ventricular tachycardia may be considered for an implantable cardioverter.

\section{Cardiac transplantation}

Dilated cardiomyopathy remains the most common indication for cardiac transplantation. This procedure was first used clinically over 25 years ago and its use has expanded considerably over the past two decades. Survival rates have improved to more than $80 \%$ at one year and to about $70 \%$ at five years. ${ }^{2}$ The quality of life is considered excellent. In fact, the likelihood of returning to normal activiies is higher than with other common forms of cardiac surgery.

Unfortunately, the morbidity of immunosuppression, the development of coronary artery disease in the allograft, and the lack of donors all limit access to this procedure by patients with congestive heart failure or adversely affect outcome. The outcome of transplantation in patients with severe (NYHA class IV) congestive heart failure is much better than with medical management, but the shortage of donors, more than any other factor, limits its wider use.

Those patients who are most likely to benefit from the procedure should be selected as recipients. ${ }^{42}$ Recipient selection criteria have been liberalised because of improvements in the pharmacological treatment of allograft rejection. In the United States, donor organs are allocated regionally and those recipients who are in the intensive care unit and receiving mechanical assistance or intravenous 
Table 3 Approach to management of dilated cardiomyopathy

- Initiate conventional management with diogoxin, diuretics, and ACE inhibitors or hydralazine/isosorbide dinitrate

- Consider $\beta$ blockade or vesnarinone if symptoms persist

- Add anticoagulation for

$\mathrm{EF}<0 \cdot 30$, history of thromboembolic phenomena, or detection phenomena, or de

If symptomatic at rest

despite above measures, despite above meas add intravenous dobutamine and/or phosphodiesterase cardiac transplantation inotropic support (status I) have the highest priority. All other patients are in a second priority category (status II). Some contend that status I patients are not the ideal candidates for major cardiac surgery and their outcome is poorer than those who are in better physiological condition at the time of operation. Careful analyses of outcomes in status I and status II patients undergoing transplantation show no difference. However, status I recipients are much more likely to die before transplantation. Consequently, the donor allocation scheme is justified.

As the treatment of congestive heart failure improves, the outcome of patients who are NYHA class III may improve to the point where transplantation is no longer warranted. Many centres now use peak oxygen uptake $\left(\mathrm{VO}_{2}\right)$ on exercise testing as a valuable index of predicting requirement for cardiac transplantation. Only patients with a peak $\mathrm{VO}_{2}<14$ $\mathrm{ml} / \mathrm{min} / \mathrm{kg}$ are regarded as candidates for cardiac transplantation. ${ }^{43}$ Even with these stringent criteria, some patients improve and may ultimately be removed from the list. There are twice as many patients added to the waiting list in the United States each month as actually undergo transplantation. If this trend continues, patients who are NYHA class III may no longer be eligible for a donor organ because of low priority. Furthermore, there was no improvement in survival after transplantation in those patients who waited more than six months for a donor organ when compared with patients who were treated medically. ${ }^{44}$ These data further imply that the transplantation waiting list should be dynamic and some patients may be listed for transplantation but removed because medical management is successful. The addition of successful oral therapeutic agents for heart failure such as $\beta$ blockade or vesnarinone warrants a prospective randomised trial comparing transplantation with medical management in status II patients. The most effective means of assuring the equitable and timely distribution of donor hearts is to treat congestive heart failure as well as possible.

\section{Summary}

Patients should be referred for cardiac transplantation only after all other means of management of congestive heart failure have been attempted and have been unsuccessful (table 3 ). An adequate therapeutic trial of conventional and experimental agents including $\beta$ blockade and vesnarinone should be completed and be shown to be unsuccessful before transplantation is considered in patients in NYHA class III. Prospective clinical trials need to be completed to define the role of newer therapeutic options. The scarcity of donor organs will probably preclude the use of cardiac transplantation in all patients who may benefit. Alternative methods of cardiac replacement (such as dynamic cardiomyoplasty, permanent implantable mechanical circulatory assistance, and xenografting) must be developed. These methods coupled with better pharmacological treatment will greatly improve the outcome of patients with dilated cardiomyopathy.

1 Report of the WHO/ISFC task force on the definition and classification of cardiomyopathies. $\mathrm{Br}$ Heart $\mathcal{F} 1980$; 44:672-3.

2 Kaye MP. The Registry of the International Society for Heart and Lung Transplantation: Ninth Official Report-1992. If Heart Lung Transplant 1992;11:
599-606.

3 Ghose RR, Gupta SK. Synergistic action of metolazone with "loop" diuretics. $B M F$ 1981;282:1432-3.

4 Lahav M, Regev A, Ra'anani P, Theodore E. Intermittent administration of furosemide vs continuous infusion preceded by a loading dose for congestive heart failure. Chest 1992;102:725-31.

5 Agostoni PG, Merenzi GC, Pepi M, Doria E, Salvioni A, Perego G, et al. Isolated ultrafiltration in moderate congestive heart failure. $₹ \mathrm{Am}$ Coll Cardiol 1993;21:424-31.

6 Coats AJS, Adamopoulos S, Radaelli A, McCance A, Meyer TE, Bernardi L, et al. Controlled trial of physical training in chronic heart failure. Circulation 1992; 85:2119-31.

7 Sullivan MJ, Higginbotham MB, Cobb FR. Exercise training in patients with severe left ventricular dysfunction. Circulation 1988;78:506-15.

8 Captopril Multicenter Research Group. A placebo-controlled trial of captopril in refractory chronic congestive heart failure. $7 \mathrm{Am}$ Coll Cardiol 1983;2:755-63.

9 DiCarlo L, Chatteriee K, Parmley WW, Swedberg K, Atherton B, Curran D. Enalapril: a new angiotensinconverting enzyme inhibitor in chronic heart failure: acute and chronic hemodynamic evaluations. $¥ \mathrm{Am}$ Coll Cardiol 1983;2:865-71.

10 The 'CONSENSUS Trial Study Group. Effects of enalapril on mortality in severe congestive heart failure. N Engl f Med 1987;316:1429-35.

11 The SOLVD Investigators. Effect of enalapril on survival in patients with reduced left ventricular ejection fractions and congestive heart failure. $N$ Engl $f \mathrm{Med}$ 1991;325:293-302.

12 The SOLVD Investigators. Effect of enalapril on mortality and the development of heart failure in asymptomatic patients with reduced left ventricular ejection fractions. N Engl F Med 1992;327:685-91.

13 Packer M. Vasodilator and inotropic drugs for the treatment of chronic heart failure: distinguishing hype from hope. F Am Coll Cardiol 1988;12:1299-317.

14 Cohn JN, Archibald DG, Ziesche S, Franciosa JA, Harston WE, Tristani FE, Dunkman WB, et al. Effect of vasodilator therapy on mortality in chronic congestive vasodilator therapy on mortality in chronic

15 Fonarow GC, Chelimsky-Fallick C, Stevenson LW, Luu $\mathrm{M}$, Hamilton $\mathrm{M}$, Moriguchi JD, et al. Effect of direct $\mathrm{M}$, Hamilton $\mathrm{M}$, Moriguchi $\mathrm{JD}$, et al. Effect of direct vasodilation with hydralazine versus angiotensin-con-
verting enzyme inhibition with captopril on mortality in verting enzyme inhibition with captopril on mortality in advanced heart failu

16 Cohn JN, Johnson G, Ziesche S, Cobb F, Francis G, Tristani F, et al. A comparison of enalapril with hydralazine-isosorbide dinitrate in the treatment of chronic congestive heart failure. $N$ Engl $f$ Med 1991; 325:303-10.

17 Cavero PG, DeMarco T, Kwasman M, Lau D, Liu M, Chatterjee K. Flosequinan, a new vasodilator: systemic and coronary hemodynamics and neuroendocrine effects in congestive heart failure. $\mathcal{f} \mathrm{Am}$ Coll Cardiol 1992; 20:1542-8.

18 Massie BM, Berk MR, Brozena S, Elkayam U, Plehn J, Kukin M, et al. Can further benefit be achieved by Kukin $M$, et al. Can further benefit be achieved by adding a vasodilator to triple therapy in CHF: Results of Circulation 1992;86:I-645.

19 Figulla HR, Rechenberg JV, Wiegand V, Soballa $R$, Kreuzer H. Beneficial effects of long-term diltiazem treatment in dilated cardiomyopathy. $\mathcal{f} \mathrm{Am}$ Coll Cardiol 1989;13:653-8.

20 Packer M, Nicod P, Khandheria BR, Costello DL, Wasserman AG, Konstam MA, et al. Randomized, multicenter, double-blind, placebo-controlled evaluation of amlodipine in patients with mild-to-moderate heart failure [abst]. F Am Coll Cardiol 1991;17:274.

21 Ferguson DW, Berg WJ, Sanders JS, Roach PJ, Kempf JS, Kienzle MG. Sympathoinhibitory responses to digitalis glycosides in heart failure patients. Circulation 1989;80:65-77.

22 Packer $M$, Gheorghiage $M$, Young JB, Costantini PJ, Adams KF, Cody RJ, et al. Withdrawal of digoxin from patients with chronic heart failure treated with patients with chronic heart failure treated with angiotensin-conve

23 Akhtar N, Mikulic E, Cohn JN, Chaudhry MH. Hemodynamic effect of dobutamine in patients with Hemodynamic effect of dobutamine in patien

24 Raifer SI, Rossen ID, Douglas FL, Goldberg LI, Karrison Rajfer SI, Rossen JD, Douglas FL, Goldberg LI, Karrison
T. Effects of long-term therapy with oral ibopamine on resting hemodynamics and exercise capacity in patients with heart failure: relationship to the generation of $N$ - 

methyldopamine and to plasma norepinephrine levels.

25 Leier CV, Huss P, Lewis RP, Unverferth DV. Druginduced conditioning in congestive heart failure. Circulation 1982;65:1382-7.

26 Applefeld MM, Newman KA, Sutton FJ, Reed WP, Roffman DS, Talesnick BS, Grove WR. Outpatient dobutamine and dopamine infusions in the management of chronic heart failure: clinical experience in 21 patients. Am Heart $f$ 1987;114:589-95.

27 Miller LW. Outpatient dobutamine for refractory congestive heart failure: advantages, techniques, and results. $f$ Heart Lung Transplant 1991;10:482-7.

28 Benotti JR, Grossman W, Braunwald E, Davolos DD Alousi AA. Hemodynamic assessment of amrinone. $N$ Engl f Med 1978;299:1373-7.

29 Gage J, Rutman H, Lucido D, LeJemtel TH. Additive effects of dobutamine and amrinone on myocardial contractility and ventricular performance in patients with severe heart failure. Circulation 1986;74:367-73.

30 Lee HR, Hershberger RE, Port JD, Rasmussen R, Renlund DG, O'Connell JB, et al. Low-dose enoximone in subjects awaiting cardiac transplantation. F Thorac Cardiovasc Surg 1991;102:246-58.

31 Packer M, Carver JR, Rodeheffer RJ, Ivanhoe RJ, DiBianco R, Zeldis SM, et al. Effect of oral milrinone on mortality in severe chronic heart failure. $N \mathrm{Engl} f \mathrm{Med}$ 1991;325:1468-75.

32 Feldman AM, Baughman KL, Lee WK, Gottlieb SH, Weiss JL, Becker LC, Strobeck JE. Usefulness of OPC8212 , a quinolinone derivative, for chronic congestive heart failure in patients with ischemic heart disease or idiopathic dilated cardiomyopathy. Am $f$ Cardiol idiopathic dilated

33 Feldman AM, Bristow MR, Parmley WW, Carson PE, Pepine CJ, Gilbert EM, et al. Effects of vesnarinone on morbidity and mortality in patients with heart failure. $N$ Engl f Med 1993;329:149-55.

34 The MDC Trial Study Group. Metoprolol in dilated cardiomyopathy [abst]. Circulation 1992;86:I-118.

35 Bristow MR. Pathophysiologic and pharmacologic rationales for clinical management of chronic heart failure with beta-blocking agents. Am f Cardiol 1993;71:12C-
$22 \mathrm{C}$.

36 Anderson JL, Gilbert EM, O'Connell JB, Renlund D, Yanowitz F, Murray M, et al. Long-term (2 year) beneficial effects of beta-adrenergic blockade with bucindolo in patients with idiopathic dilated cardiomyopathy. $\mathcal{F} \mathrm{Am}$ Coll Cardiol 1991;71:1373-81.

37 Heilbrunn SM, Shah P, Bristow MR, Valantine HA Ginsburg $R$, Fowler MB. Increased $\beta$-receptor density and improved hemodynamic response to catecholamine stimulation during long-term metoprolol therapy in heart failure from dilated cardiomyopathy. Circulation 1989;79:483-90.

38 Gilbert EM, Olsen SL, Renlund DG, Bristow MR. Betaadrenergic receptor regulation and left ventricular function in idiopathic dilated cardiomyopathy. $A m \Im$ Cardiol 1993;71:23C-9C.

39 Falk RH, Foster E, Coats MH. Ventricular thrombi and thromboembolism in dilated cardiomyopathy: prospective follow-up study. Am Heart $\mathcal{f}$ 1992;123: $136-42$

40 Costanzo-Nordin MR, O'Connell JB, Engelmeier RS, Moran JF, Scanlon PJ. Dilated cardiomyopathy: functional status, hemodynamics, arrhythmias, and prognosis. Cathet Cardiovasc Diag 1985;11:445-53.

41 Stamato NJ, O'Connell JB, Murdock DK, Moran JF, Loeb HS, Scanlon PJ. The responses of patients with complex ventricular arrhythmias secondary to dilated cardiomyopathy to programmed electrical stimulation. Am Heart f 1986;112:505-8.

42 O'Connell JB, Bourge RC, Costanzo-Nordin MR, Driscoll DJ, Morgan JP, Rose EA, Uretsky BF. Cardiac transplantation: recipient selection, donor procurement, and plantation: recipient selection, donor procurem

43 Mancini DM, Eisen $H$, Kussmaui W, Mull R, Edmunds Jr. LH, Wilson JR. Value of peak exercise oxygen consumption for optimal timing of cardiac transplantation in ambulatory patients with heart failure. Circulation 1991;83:778-86.

44 Stevenson LW, Hamilton MA, Tillisch IH, Moriguchi JD, Kabashigawa JA, Creaser JA, et al. Decreasing survival benefit from cardiac transplantation for outpatients as the waiting list lengthens. F Am Coll Cardiol 1991, 18:919-25. 